\title{
Dois homens combatendo: Goya e Kafka e o homem engolido pela história
}

\author{
Pedro Henrique Reis ${ }^{1}$
}

\section{RESUMO}

Este trabalho busca construir uma relação entre individualidade e gregarismo, modernidade e pós-modernidade, tomando como exemplos artísticos a pintura de Francisco José de Goya y Lucientes, Duelo a Garrotazos (1820-1823), e a curta narrativa de Franz Kafka, Ele - Notas de 1920 (1923). O esforço aqui empreendido é em buscar uma chave de interpretação para formas artísticas e culturais (incluindo produtos midiáticos em suas múltiplas representações e metáforas), dentro do escopo das transformações vividas no Ocidente desde o período da Renascença.

Palavras-chave: Modernidade; Pós-Modernidade; Individualismo; Gregarismo.

\begin{abstract}
The present work tries to build a relationship between individuality and gregariousness, modernity and post-modernity, taking as artistic examples the painting by Francisco José de Goya e Lucientes, Duelo a Garrotazos (1820-1823) and the short-story by Franz Kafka, Ele - Notas de 1920 (1923). The effort here is to search for an interpretation key for artistic and cultural forms (including the multiple representations and metaphors of media culture products) inside the scope of the transformations lived in western culture since the Renaissance.
\end{abstract}

Keywords: Modernity, Post-modernity, Individualism, Gregariousness.

\section{INTRODUÇÃO}

Antes tomou parte de um grupo monumental. Em torno a um pináculo agrupavam-se em ordem estudada as figuras do guerreiro, das artes, ciências e ofícios. Um desses do grupo era ele. Há tempo que o grupo se dissolveu; ao menos ele já não o integra. Não conserva já seu antigo ofício, esqueceu qual era o seu papel no grupo. Precisamente por esse esquecimento sobrevem certa tristeza, incerteza, inquietude, certa nostalgia dos tempos passados que entenebrece o presente. E contudo esta nostalgia é importante elemento da força vital ou porventura ela mesma.

(Franz Kafka)

\footnotetext{
${ }^{1}$ Jornalista, mestre e doutorando em Comunicação (PUC-RS).
} 
Ao pensarmos nos fenômenos de transformação da condição humana durante os últimos cinco séculos, somos levados a ponderar duas questões importantes: o gregarismo, o aspecto coletivista da existência humana e sua contraparte, o individualismo, o homem como sujeito, como átomo. Pretendemos aqui partir da pintura de Francisco José de Goya y Lucientes (1746-1828), “O Duelo a Garrotazos” (1820-1823) e de uma pequena narrativa, uma parábola, de Franz Kafka (1883-1924), intitulada "Ele - Notas de 1920”, que nos servirão como uma possível senha para pensar não apenas essa dualidade como todo o trajeto histórico que o Ocidente vivenciou desde o final da Idade Média. O objetivo aqui é amarrar estas duas obras, estes dois formatos artísticos, aos seus períodos históricos e às considerações teóricas para que elas possam servir de objeto de análise e compreensão acerca das relações do homem com a história e a tradição.

A pintura de Goya, inserida entre o século XVIII e o início do XIX, transmite a ansiedade imanente do conflito que esta época experimentou acerca não apenas da dualidade política e social, com as transformações dos estados-nação e das lógicas econômicas e culturais, assim como a perda dos referenciais metafísicos. Combatendo de forma alucinada, eles brilham empunhando suas armas; porretes mal feitos e tortos se movendo no ar prontos para desferir o golpe fatal e, ainda assim, eternamente inertes.

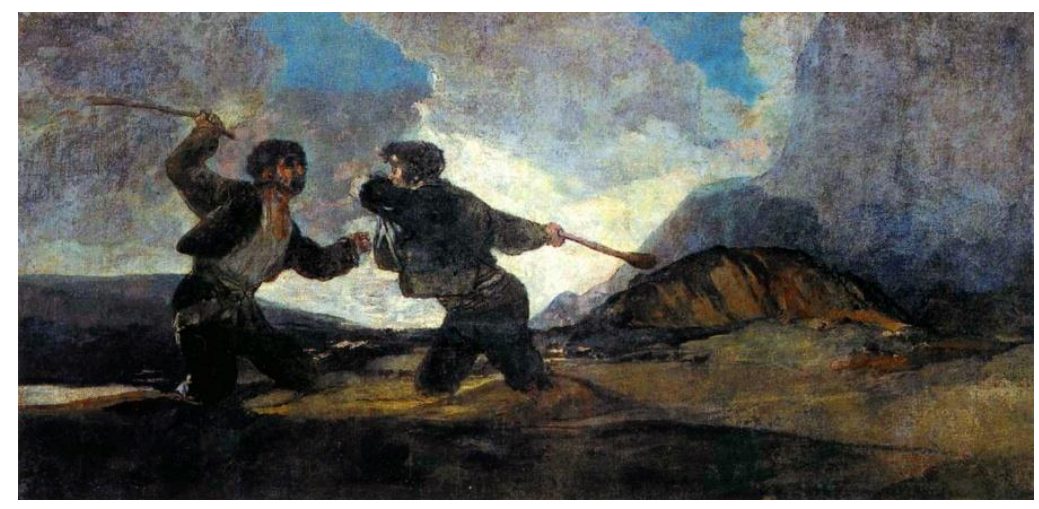

Michel Serres nos indicará uma senha essencial a percepção desta obra e que nos balizará: assim como a de Aquiles, a verdadeira batalha é contra a lama. Nenhum deles percebe "como se enterram na lama [...] todos juntos" (SERRES, 1990, p. 20). A tela exprime, em certo sentido, uma batalha já acabada. "Os beligerantes não advinham o abismo em que se precipitam, mas do exterior, nós, pelo contrário, vemo-lo bem” (idem, p. 11). É a história que os engole. 
Temos aí um dos pontos. O outro nos será introduzido por Hannah Arendt, que nos levará, então, a outra senha: a metáfora que Franz Kafka desenvolve na última de uma série de "Notas do ano 1920" (ARENDT, 2009), intitulada He (ou Ele). Neste pequeno texto Kafka tece a parábola de um homem, nomeado apenas como Ele:

Tem dois inimigos: o primeiro ameaça-o por trás, desde as origens; o segundo fecha-lhe o caminho para diante. Luta contra ambos. Na realidade, o primeiro apoia-o em sua luta contra o segundo, quer impeli-lo para diante e da mesma maneira o segundo o apoia em sua luta contra o primeiro, empurra-o para trás. Mas isto é somente teórico. Porque além dos adversários também existe ele, e quem conhece suas intenções? Sempre sonha que em um momento de descuido - para isso faz falta uma noite inimaginavelmente escura - possa safar da linha de combate e ser elevado, pela sua experiência de luta, por cima dos combatentes, como árbitro (KAFKA, 2000, p. 220).

O Ele deseja apenas uma linha vertical que possa removê-lo da horizontalidade que não lhe permite perceber a luta e a quem favorecer e quando.

É aqui onde se insere a semente da indagação que procuramos fazer: estas obras, tanto a curta narrativa de Kafka, quanto a sedutora obra de Goya, situadas historicamente na pedra angular das transformações que a modernidade sofreria ao final do século XIX e ao longo do XX, interpelam o sentido da própria história e do homem como sujeito ativo e passivo nela. O contendor, podemos concordar, da esquerda é o adversário kafkiano de trás, e o outro, logicamente, o da frente.

Em Goya passado e futuro se afogam no lamaçal do presente, tradição e projeção esfacelam-se em favor de um presenteísmo esmagador que os engole indiscriminadamente, de forma incólume e anônima. Em Kafka, entretanto, é o sujeito, acertadamente nomeado Ele, que sonha com uma "noite inimaginavelmente escura" quando ou onde ele possa ser "árbitro" da contenda. O que percebemos é um índice, uma senha para entendermos os Weltenschauung, as visões de mundo, no sentido de uma "ideologia total" (MANNHEIM, 1971, p. 82), que permeiam as tentativas contemporâneas de entender as transformações históricas e da condição humana, principalmente acerca da idaia de um sujeito, nas palavras de Heidegger, jogado no mundo, e como esse sujeito se relaciona com as ideias de passado, presente e futuro: em suma, como o homem, em seu aspecto coletivo e individualizado, lida com a tradição e com a projeção. 
Essas ponderações têm como objetivo traçar um paralelo histórico entre os períodos vividos por Goya e Kafka - as obras aqui, como dito, serão propostas como marcos históricos - que abarquem duas importantes questões que se relacionarão com essa perspectiva; a primeira, portanto, será o do individualismo. A segunda, por conseguinte, serão os processos de religação e de gregarismo. Para tanto faremos um percurso partindo das obras e constituindo dois momentos analíticos que permitam emergir a temática proposta e perceber esses polos da experiência moderna.

\section{GOYA: DO HOMEM ESMAGADO PELO MUNDO À EMANCIPAÇÃO MODERNA}

Partamos, então, da tela de Goya. O duelo se dá entre dois homens, jogados no mundo, com suas vestes arbitrárias e suas armas, simbolicamente, das mais simples. Eles guerreiam. São, numa primeira e superficial análise, o retrato da alteridade. Um retrato emoldurado por uma natureza engolidora e indiferente - um por ou nascer do sol recoberto de nuvens amareladas e negras. As montanhas se desenham como manchas e o solo, quase estéril. A contenda, de fato, se dá sobre um solo movediço. Lama, areia movediça. O traço que brinca entre o claro e o escuro - brinca também neles: um, iluminado, mas quase virado de costas, o outro, escurecido, mas com o corpo voltado para frente. Seus braços desenham no ar uma invisível simetria que corta a tela com a dureza do embate. Poderia ser afirmado que ambos se encontram frente a um espelho.

Francisco José de Goya y Lucientes nasce no século XVIII e morre no XIX. Decerto, viveu e morreu no ínterim entre as Luzes e a Modernidade já opaca; seus primeiros trabalhos, límpidos e permeados de um realismo quase estático, retratavam a nobreza e a aristocracia espanhola. A invasão francesa modificou sua visão de mundo: a partir de maio de 1808 a falta de movimento, quase contemplativa, de seus trabalhos é substituída pela ação. As telas “Dois de Maio 1808” (1814) e "Três de Maio 1808” (1814) mostram sangue, desespero, urros. Não estranhamente, depois, o mestre se entregará às sombras que víamos em "Courtyards with Lunatics" (1794), de certo, ele aplacará a parte maldita do mundo em telas como "Saturno Devora seu Filho" (1819-1823).

A morte, a escuridão, a dor e o movimento permeiam suas obras, mas nenhuma, e é aqui que encontramos o marco, denota tanta subjetividade como a tela em questão, "Duelo a Garrotazos", que pode ser simplesmente traduzida como duelo com 
bastões. Os dois homens, enterrados até os joelhos, batalham em simetria, quase escondidos pelas nuvens pesadas que remetem a uma tempestade chegando ao final do dia. Os movimentos parecem desesperados, alucinados: nenhum parece perceber que o vencedor e o perdedor da contenda terá o mesmo destino - serão engolidos. E, talvez, o destino certo e comum dos dois seja, de fato, secundário; é a batalha que importa para eles, a contenda, o conflito.

Inspirado, certamente, pela invasão francesa e a despeito de suas inúmeras identificações com os movimentos artísticos românticos, Goya denuncia e, podemos dizer também, anuncia, a inocência do devir, a aceitação do amor fati nietzscheano. "Consenso nesse plano a esse mundo" (MAFFESOLI, 2010, p.6), no qual os dois jogadores estão jogados. Presenteísmo que remete ao que era vivido na época: o ardor das paixões nacionalistas que nasciam com o fim do poder da Igreja e o início do poder da razão; razão, aqui, para lutar. Os lutadores são o passado e o futuro, lutando alucinadamente sobre o palco movediço do presente e sob o entardecer da história, que engole tudo.

Estamos, portanto, falando de emancipação. E, para tanto, é preciso antes de tudo levantar dois importantes e distintos momentos emancipatórios. É seguro dizer que a maior parte da história humana obedeceu a uma lógica gregária e estrita, de laços de sangue, pequenas comunidades ou grupos de comunidades, geralmente fechadas; sociedades altamente hierarquizadas em torno de uma tradição comum permitiam liberdade e acesso a pouquíssimos ${ }^{2}$. Entretanto, a realidade é que o sujeito, o indivíduo, pelo menos até o período entendido como modernidade, estava totalmente sujeito ao mundo e sujeito ao seu grupo ou tribo originária: "Não era preciso que o universo se armasse para o esmagar: um vapor, uma gota de água bastava para o matar; engolido como um ponto, era este o homem de ontem, vencido pelo clima na guerra travada entre ambos" (SERRES, 1990, p. 35).

Estes homens, portanto, estavam "imersos no estar-no-mundo, ligados indissoluvelmente um-com-o-outro" (idem). Temos, então, que o primeiro desses momentos emancipatórios foi uma recuperação do classicismo greco-romano que remonta às revolução iniciadas durante a Renascença. Foi o início de uma revolução do tempo que levará, a grosso modo, mais de cinco séculos para se concretizar em uma

\footnotetext{
${ }^{2}$ Claro que devemos excetuar a experiência grega, manifesta através de seus narradores últimos (nas vozes de Platão e Aristóteles, principalmente), seguida dos processos legislativos e republicanos de Roma, que demarcam um importante momento de libertação do homem, em suas ideias individualistas e em seu papel, principalmente político, dentro de uma sociedade agregadora.
} 
transformação da sociedade, na qual, através da gradual liberação "do fardo do trabalho", incitada pelos avanços em termos técnicos e científicos, "a massa da população se incorpora" (SHILLS apud ARENDT, 2009, p. 250) a ela. Primeiro essa incorporação modifica e liberta o homem das proposições metafísicas que ordenavam a realidade. $\mathrm{O}$ momento vivido por Goya foi um momento em que "O poder, em outras palavras, não vinha mais do céu, mas de baixo, da terra, do povo, da união das vontades que formavam a coletividade nacional" (FINKIELKRAUT, 1989, p.23).

Esse período, antes de ver a derrocada das monarquias e da governabilidade baseada na religião - principalmente católica e protestante - vai encontrar a desconfiança e as exigências de mobilidade social e participação de conjuntos sociais, até então, esmagados pela força das hierarquias. Aos moldes de Rousseau e Stuart Mill, essa primeira emancipação será vivida como uma "rebelião declarada contra a sociedade" (ARENDT, 2009, p.251) que encontrará eco nas atitudes revolucionárias (primeiro, da plebe, de cunho democrático e libertário, depois dos trabalhadores, estas de cunho socialista-comunista), no capitalismo liberal das burguesias que ganhavam espaço a partir do desaparecimento das aristocracias europeias, no nacionalismo que desembocará no totalitarismo visto desde os anos 1930. Decerto, é o surgimento de narrativas soteriológicas de cunho laico; todas, de uma forma ou outra, atreladas à nova coroa: a razão.

O que a tela do espanhol retrata é o nascimento da concepção do homem moderno, um marco da modernidade. Sua emancipação, entretanto, não era ainda do "neoindividualismo", atrelado a uma plena "construção de si", uma "tomada de posse do seu corpo e de sua vida" (LIPOVETSKY, 2004, p. 20). A despeito de ser uma emancipação daqueles caracteres metafísicos (moral cristã católica, monarquia, governos baseados em decretos divinos: basicamente é a libertação dos caracteres tradicionais) e uma emancipação do tempo (com o avanço técnico-científico, personificado, ao final, pela revolução industrial), trata-se de libertar o homem de um conjunto de explicações para encarcerá-lo em outro. Esse período vai ver o surgimento, como dito, de ideologias agregadoras que demandam ação direta sobre as condições de vida.

Essa emancipação, que podemos mesmo dizer uma emancipação do tempo, que liberta o homem relativamente jogando-o num mundo novo e sem perspectivas, é, marcadamente, também uma emancipação da tradição. Esta, ligada há muitos séculos ao que indicava as identidades desses grupos, se esfacela. A era da razão, a modernidade, 
também é a era da salvação pela razão, da racionalização das identidades. Marxismo, liberalismo, capitalismo, nacionalismo; esses serão os substitutos da tradição. A herança da razão é legada a geração deste entre-séculos sem um testamento claro, sem um manual instruções, e ela será vivida no coração de todas as ideologias, de todas essas metanarrativas que procurarão, de uma forma ou de outra, explicar o mundo e planejar o futuro.

Apenas ao final do século XX, depois dos levantes comunistas e das exasperações nacionalistas (algumas totalitárias, outras também esquerdistas-marxistas e, ainda, algumas mesmo democráticas) que essas meta-narrativas vão encontrar, então, a sua derrocada, e encontraremos um segundo momento de emancipação. Liberalismo, democracia, nacionalismo, esses grandes sistemas explicativos passariam, então, pela mesma desconfiança que os sistemas metafísicos sofreram quatro séculos antes.

É uma mudança de registro, é uma emancipação do pensamento em relação a esses referenciais herdeiros da razão, principalmente no que eles têm de ideologia total, de uma visão de mundo. A bomba atômica e a divisão do átomo e a dobradura da luz confirmam e popularizam a relatividade que se instaura nas sociedades ocidentais de forma transmutada. O ponto de vista, o valor da vida (reminiscência do cristianismo), em suma, "a ideologia dos Direitos do Homem, nas sociedades liberais, triunfa sem contestação" (LIPOVETSKY, 2004, p.23).

Estamos, então, finalmente, depois de uma emancipação do tempo, aliada ao avanço técnico-científico, e de outra mental, aliada à derrocada dos sistemas tanto metafísicos quanto racionais de explicação e projeção do mundo, em uma era em que a questão é a do sujeito individual. As propostas dos "filósofos das Luzes" desmanchamse, os universalismos são combatidos em prol das particularidades - em prol do homem, ainda que fruto de uma nação ou cultura - mas um homem: uma parcela de uma vontade. Estamos, então, numa época de paradoxos, onde a "humanidade deve se declinar no plural: ela não é senão a soma dos particularismos que povoam a terra" (FINKIELKRAUT, 1988, p.27-28) e onde precisamos, então, perceber dialeticamente um outro conjunto de fenômenos.

\section{KAFKA: O HOMEM MODERNO, BARBÁRIE E RETORNO}


Partamos, então de Kafka. Franz Kafka, nascido em 1883, apenas cinco anos após a morte de Goya, viveu até 1924. Viveu, portanto, como o mestre espanhol, entre séculos - o XIX e o XX. Os resultados dos conflitos vividos por Goya serão vividos por Kafka; a parábola kafkiana, sem dúvida, remete ao pavor do fim da história: o Ele kafkiano se vê desabilitado de lidar com a herança de um passado que quase o atropela, empurrando-o para um futuro igualmente despropositado que, ao invés de convidá-lo e abraçá-lo como a herança iluminista aponta, bloqueia-o e contesta a força do passado.

Precisamos, então, nos perguntar: aqueles momentos emancipatórios levamnos a algo que pode ser entendido como um paradoxo? Um retorno ético, nas palavras de Edgar Morin? Alguns entenderão o individualismo se transformando em hiperindividualismo, uma lógica que se espiralizaria em processos tênues e superficiais de religação (LIPOVETSKY, 2004b, p.20). O fato é que devemos, no fundo, perceber o embate: é possível dizer apenas isso? Cabe decifrar as perdas referenciais da Renascença ao Iluminismo, do romantismo idealista (predominantemente alemão) ao racionalismo calculista, como apenas processos emancipatórios que, ao englobarem as massas no jogo econômico e político das sociedades, libertam apenas o indivíduo para que este possa viver sua existência de forma totalmente individualizada?

O homem de Kafka, o Ele, está sozinho em sua luta. Seus adversários podem ser descritos como sujeitos, mas são as intenções desse Ele que contam. De fato entra no jogo, usando o termo no tom proposto por Maffesoli, o sentimento. Não é cabível perceber apenas um paradoxo, é necessário precisar uma adaptação. É preciso mesmo que se conceba "outra alternativa a essa relação com o mundo senão a ordem disciplinar e o rigor das convenções" (FINKIELKRAUT, 1988, p.146); além da mera dualidade, de um diálogo intermitente entre indivíduo e sociedade, entre sujeito e coletivo, é preciso exceder o paradoxo duplo: não é "esgotamento do individualismo", nem mesmo “disseminação da sua dinâmica" (LIPOVETSKY, 2004b, p.20) em espirais esvaziadas.

\footnotetext{
Ante a impermanência de todas as coisas e de cada um, existem diversas estratégias: a que projeta para o futuro e se volta para o céu, a que se contenta com o presente e se enraíza na terra. Aquela é "uraniana" (celeste) e favorece um ideal a ser alcançado; esta é "ctoniana" (terrestre) e se interessa pelo que está perto, pelo vivido, pelo que está "aqui e agora" (MAFFESOLI, 2004, p.46).
}

O que o texto de Kafka nos mostra é essa dualidade: o homem, esmagado na linearidade do tempo e sua vontade, seu objetivo, em si, sua vida. Relacionando aqui com 
o que Maffesoli quer nos mostrar, teremos a relação íntima entre a forma como uma sociedade almeja e reforça sua própria história, essas narrativas, e o seu papel agregador. Ele interpela o sentimento. Com as referências acabadas, e é isso que vai marcar indelevelmente o conjunto de fenômenos circunscritos como pós-modernidade. Dilaceradas em seu caráter mecanicamente agregador ou, nas palavras de Hannah Arendt, em suas exigências por ação direta, o indivíduo, do qual falávamos no primeiro segmento deste trabalho, se vê emancipado do tempo (a diminuição das exigências laborais e a transformação da sociedade em sociedade de massas ajudam-no a voltar a participar ativamente da cultura, mais precisamente, da cultura de consumo) e se vê, igualmente, emancipado mentalmente (fora dos polarismos que marcam, também indelevelmente, a modernidade, e jogado no mundo; de fato, em diversas visões de mundo, este indivíduo vivencia isso sem estar mais atrelado à ação direta ou a uma objetivação abstrata: trata-se de mundos fluidos, migrantes).

Kafka aponta, principalmente nestes textos para uma nova batalha que se desenha. Nas palavras de Arendt, “"Ele’ não tem espaço” (ARENDT, 2009, p.37), a metáfora começa quando "já transcorreu o curso da ação" (idem, p. 34), sua única escapatória é para o terreno pantanoso e "desprovido de sentido" (idem, p. 35) da metafísica, de um retorno equivocado a explicações que já foram descartadas. Decerto, o que a metáfora kafkiana nos traz é que o Ele não é apenas o sujeito individualizado, pois "quando, afinal, rompeu-se o fio da tradição, a lacuna entre o passado e o futuro deixou de ser condição peculiar unicamente à atividade do pensamento e adstrita, enquanto experiência, aos poucos [...] que fizeram do pensar sua ocupação primordial” (idem, p. 40).

A batalha se dá e se deu entre o particular e o universal. Antes de ser um mero retorno ao gregarismo tribal, a um mundo anterior a Roma, anterior ao feudalismo, o que fundamentalmente deve ser percebido é que se trata de um retorno ao embate que fez nascer a modernidade. De forma alguma o cosmopolitismo das Luzes brilhava como único farol: a instrumentalização da razão se contorcia com o nacionalismo, a voz de Voltaire, Kant e Descartes chocava-se com o clamor de Herder e de Maistre. O Homem em conflito com o homem - iluminismo e racionalismo, idealismo e romantismo. $\mathrm{O}$ Homem total das Luzes perde o foco no embate que faz nascer o que talvez seja a última fase da Modernidade: o nacionalismo totalitário onde, "pela primeira vez, não é nem a 
demonstração da força, nem o direito divino que o Estado opõe à vontade dos indivíduos, é sua própria identidade" (FINKIELKRAUT, p.54).

O Ele kafkiano aguarda a noite mais escura para que ela possa deliberar sobre o conflito, entretanto, a resolução é clara. Homem, espectador, passado, futuro, presente: a história engole a tudo e é aqui que vemos um marco da pós-modernidade. Seu "presenteísmo", seu barbarismo, sua entrega: agora e nada mais. Identidade nacional? A identidade se torna identificação. Não há mais antes, não há mais blueprint do depois: há apenas agora. O consumo é imediato, a ética é imediata; cultura humana, diria Ernest Renan (apud FINKIELKRAUT, 1988, p.46).

\section{COEXISTÊNCIA E COALESCÊNCIA}

Partamos, então, a abertura do último capítulo da modernidade para que assim confrontemos o Homem, universal, total, o ser abstrato da proposição iluminista e o homem identitário de Herder e do romantismo com o homem racional e liberto, das narrativas obliteradas, e o homem do gregarismo voluntário, do estar-junto. Precisamos, portanto, não confundir.

Aqueles momentos de emancipação precisam, antes de tudo, serem vistos também como visões de mundo: Iluminismo e Romantismo, Modernidade e PósModernidade. Verdadeiro paradoxo? Trata-se, de fato, de um retorno a Anschlusswert (MORIN, 2005, p.22), ao valor da religação. Retorno de uma "sólida e rizomática solidariedade orgânica” (MAFFESOLI, 2010, p.8). Uma religação ética, voltada a transformar a condição física e mental dos homens, que se coloca nos escombros do nacionalismo.

A privação do totalitarismo se torna ainda outro momento emancipatório: nas palavras de Ayn Rand: "somos todos irmãos sob a pele, e eu estaria disposta a esfolar a humanidade para provar”. É, novamente, o sentimento; fio condutor dessa religação através de um "essencial inaparente das aparências. Estas da vida cotidiana. Estas desses prazeres miúdos [...] constituindo o humano onde cresce o estar-junto" que repousa "sobre uma partilha de sentimentos diversos" (MAFFESOLI, 2007, p.10 e p. 8) e que finalmente se propõe a resolver o problema duplo: entre o indivíduo e o coletivo, entre o local e o universal. 
Não há um motor da história; ela mesma é o motor. É errado, e passível dessa afirmação, desistorizar. Retirar esses momentos, esse fluxo, de seus caracteres históricos, das ideologias latentes (e às vezes tácitas) que permeiam as proposições de homem. Modernidade, Pós-Modernidade: estes são termos abstratos que se referem a conjuntos de fenômenos e seria uma simplificação grosseira procurar seus marcos delimitantes. Recortar a atualidade e tentar entendê-la como dois períodos em separado, uma pósmodernidade tosca e frívola colocada em contraste a um exagero de modernidade não contempla a realidade imanente de que estes dois períodos, esses dois conjuntos de fenômenos, se entrelaçam.

\begin{abstract}
Seria [...] incorreto definir a natureza do pensamento em geral com base [numa] situação histórica especial em que se permitiu a um modo de pensar relativamente individualizado desenvolver-se em condições excepcionais. Seria forçar os fatos históricos [...]. Não conseguiremos atingir uma Psicologia e uma teoria do conhecimento inteiramente adequadas, enquanto nossa Epistemologia deixar, desde o início, de reconhecer o caráter social do conhecer e não encarar o pensar individualizado como apenas um momento excepcional (MANNHEIM, 1972, p.59).
\end{abstract}

Não devemos, portanto, perder de vista o caráter ideológico. Devemos aplacar a derrocada das narrativas, primeiro, metafísicas, a morte de Deus, e, depois, racionais, que não implicam no desaparecimento total de polarizações ideológicas. Numa senda tocquevilleana, deve-se, de fato, aceitar uma coexistência de contrários como qualidade inerente e indelével que resultou da democratização do Ocidente. Imputar que o presente seja a única alternativa e que o futuro está nas mãos de uma "dinâmica técnica e científica" (LIPOVETSKY, 2004, p.68) não acarreta o desaparecimento do caráter ideológico e muito menos político. É o cotidiano que se politiza, se intensifica numa agregação de presente e futuro, numa dilatação do passado. "A antinomia dos valores não poderá jamais resolver-se e, finalmente, é em função desta mesma antinomia que as sociedades perduram. De modo substantivo e um tanto insolente, digamos que, enquanto os deuses se guerreiam, os homens estão tranquilos” (MAFFESOLI, 2007, p.181).

Individualismo ou gregarismo, modernidade ou pós-modernidade: a senha não é uma ideologia particular, uma mentira ou ilusão. É uma ideologia total, como nos apresenta MANNHEIM: "uma correspondência entre uma dada situação social e uma dada perspectiva" (1972, p. 84). Antes de entendermos uma era do vazio, aos moldes de Lipovetsky, arregimentada entre um presenteísmo fatalista ou, como dizíamos no segmento anterior, cativo de uma "ordem disciplinar" e de um "rigor das convenções" 
(FINKIELKRAUT, 1988, p.146), na qual o indivíduo impera de forma "pós-moralista" (LIPOVETSKY, 2004b, p.27), centralizado nesta atomização, precisamos entender a força do vazio: "O próprio do trágico, que bem traduz a presença de um mal incontornável, refere-se essencialmente a força da alteridade, ou seja, ao fato de que em cada coisa, em cada situação, existe seu contrário" (MAFFESOLI, 2004, p.62-63).

Nesta genealogia entre Renascença, Modernidade e Pós-Modernidade, como Finkielkraut, de certa forma, aponta, devemos desenterrar exatamente essa coabitação de contrários: indivíduo e coletivo. Mais do que definir momentos emancipatórios do indivíduo, mais do que ressaltar esse retorno ético que religa os homens através de processos de identificação, devemos tomar a tela de Goya e a parábola de Kafka como caracteres históricos desses fenômenos afim de entender esse diálogo. Devemos entender que ambas as metáforas acontecem quando a ação já terminou: ao Ele, resta a estafa de uma situação impossível, aos combatentes, lhes resta apenas serem engolidos pela lama.

Aos lutadores, o fim da tirania de uma identidade externa; ela se torna identificação. As batalhas do presente são travadas pelo presente: não mais por um "tesouro perdido", como bem coloca Hannah Arendt, nem mesmo por um futuro idealizado. Sozinhos, eles são seus próprios exércitos, suas próprias nações. O Ele, ao homem, o indivíduo, está preso mesmo ao presente: entre forças igualmente esmagadoras de um passado que lhe lança em direção ao futuro e um futuro que lhe quer preso ao passado; lhe resta "sonhar", como bem coloca Kafka. Planejar, projetar, almejar - traçar um plano para que possa erguer-se "por cima dos combatentes". Porém, isso é impossível. Ou, no mínimo, bastante improvável. A "noite inimaginavelmente escura" não pode jamais chegar já que Ele e seus dois adversários estão em meio às luzes. Uma que direciona para frente, outra para trás. Nas palavras de Arendt, “"ele’ não tem espaço”, a metáfora começa quando "já transcorreu o curso da ação", sua única escapatória é para um terreno pantanoso e "desprovido de sentido". De certo, o que a metáfora kafkiana nos traz é que "quando, afinal, rompeu-se o fio da tradição, a lacuna entre o passado e o futuro deixou de ser condição peculiar unicamente à atividade do pensamento e adstrita, enquanto experiência, aos poucos [...] que fizeram do pensar sua ocupação primordial" (ARENDT, 2009, p. 40).

Em certo sentido, temos aqui um paralelo de entre dois séculos, entre o XIX e o XX, entre os anos 1820-1830 e 1920-1930, que ecoa também nas palavras do poeta francês René Char (1907-1988), durante seus anos na resistência francesa ao avanço 
nazista, e de Aléxis de Tocqueville (1805-1859). 'Notre héritage n'est precede d'aucun testament" avisa o poeta francês aproximadamente 100 anos depois do também francês, aquele pensador político e historiador, dizer: "Desde que o passado deixou de lançar sua luz sobre o futuro, a mente do homem vagueia nas trevas" ${ }^{4}$.

Não é apenas a herança das Luzes, mas também a herança romântica que se rompe. É esta tradição que protegia aquele homem do qual Serres nos falava no início desta discussão. Aquele homem estava mesmo jogado no mundo e sua pequenez só podia ser caracterizada como minúscula: seu corpo, sua voz - tudo limitado pela força inegável da natureza. A tradição, seu povo, seu gregarismo inato, étnico e inescapável era sua condição de força, sua guia de valores. Agora, depois de uma turbulenta modernidade, com este fio partido, com sua Erfahrung, a experiência, nas palavras de Walter Benjamin, destroçada e jogado apenas na sua Erlebnis, na vivência, no termo optado por Michel Maffesoli, os "tesouros e qual seu valor" (idem, p. 31) se perdem como cristais quebrados num solo quebradiço. Resta apenas a imperatriz tríplice: religação, sentimento e pertencimento.

Seja como for, para desencobrirmos estas relações subterrâneas, este vai-evem entre socialidade obscura e individualismo aparentemente exacerbado, deveríamos partir de um início - de um princípio de um princípio, em termos agostianianos - que tenha a maturidade de focar e desfocar o papel do que Mannheim nos baliza como ideologia total ou Weltanschauung, a visão de mundo, na construção e desconstrução dessas noções. É necessário, antes de tudo, abarcar a unidade e o múltiplo, o uno e o diverso, o mesmo e o outro, a diferença e a repetição, o poder do que se esconde sobre e sob essas relações, de forma mais enraizada do que propriamente dialética. O homem atomizado ou reencontrado no seio de socialidades solidárias e voluntárias: "a barbárie acabou por se apoderar da cultura" (FINKIELKRAUT, 1988, p.159) e a questão central talvez deva ser a de uma ilusão de coletivo e de uma desilusão de indivíduo, de uma relação da cultura com a história e de como a história, como as areias em Goya, como a noite em Kafka, engole tudo e todos. Ou seja, talvez antes de postularmos a intensificação tanto de um individualismo frio e calculista quanto de um novo gregarismo ético e idílico

\footnotetext{
${ }^{3}$ Esta citação, traduz-se por "Nossa herança nos foi deixada sem nenhum testamento".

${ }^{4}$ Esta citação é do último capítulo de Democracia na América. Tanto esta citação como a anterior de René Char são citadas por H. Arendt, Op. Cit., p. 28 e p.32, respectivamente.
} 
devamos contextualizá-los no jogo, na luta: fio quase linear que dança, então, sobre a tensão esmagadora do tempo.

\section{REFERÊNCIAS}

ARENDT, Hannah. Entre o passado e o futuro. São Paulo: Perspectiva, 2009.

. A promessa da política. Rio de Janeiro: DIFEL, 2009.

FINKIELKRAUT, Alain. A derrota do pensamento. Rio de Janeiro: Paz e Terra, 1988.

KAFKA, Franz. A muralha da China. Belo Horizonte: Itatiaia, 2000.

LIPOVETSKY, Gilles; CHARLES, Sébastien. Os tempos hiper-modernos. São Paulo: Bacarolla, 2004a.

LIPOVETSKY, Gilles. Metamorfoses da cultura liberal: ética, mídia e empresa. Porto Alegre: Sulina, 2004b.

MAFFESOLI, Michel. O conhecimento comum: introdução à sociologia compreensiva. Porto Alegre: Sulina, 2007.

A parte do diabo. Rio de Janeiro: Record, 2004.

Revista Famecos, Vol. 17, No. 01, 2010.

MANNHEIM, Karl. Ideologia e Utopia. Rio de Janeiro: Zahar, 1972 [1960].

MORIN, Edgar. O método 1: a natureza da natureza. Porto Alegre: Sulina, 2005.

O método 6: ética. Porto Alegre: Sulina, 2005.

SERRES, Michel. O contrato natural. Lisboa: Instituto Piaget, 1990. 